\title{
THE STATUS OF IODINE NUTRITION AND IODINE DEFICIENCY DISORDERS AMONG SCHOOL CHILDREN IN METEKEL ZONE, NORTHWEST ETHIOPIA
}

\author{
Girma Kibatu ${ }^{1}$, Endalkachew Nibret ${ }^{2}$, Molla Gedefaw ${ }^{3}$
}

\section{ABSTRACT}

BACKGROUND: Iodine deficiency disorders are serious public health problems in Ethiopia. The aim of this study was to measure the prevalence and severity of iodine deficiency disorders among school children in Metekel Zone.

METHODS: A cross-sectional school based descriptive study was conducted between February 2011 and July 2012. One school containing 750 children aged between 6 and 18 years was randomly selected. Two hundred students from this school were selected by systematic random sampling. Physical examination was made according to WHO goiter classification system; 50 salt samples from households to which the sampled children belonged were tested for iodine using rapid field test kits and titration; a casual urine sample $(5 \mathrm{ml})$ was taken from 30 children to measure urinary iodine spectrophotometrically, and $5 \mathrm{ml}$ venous blood sample were collected from 37 children to measure thyroid relevant blood constituents using ELISA.

RESULTS: The total goiter prevalence was 39.5\%; $60 \%$ of the salt samples contained no iodine. The median urinary iodine concentration ranged from $20.54-62.2(39.9 \mu \mathrm{g} / \mathrm{L})$. School children who were assessed for thyroid hormones showed $18.92 \%$ elevated and $27.03 \%$ suppressed TSH levels.

CONCLUSION: The study demonstrated that iodine deficiency is still a severe public health problem in Metekel Zone. There is a need to further strengthen the existing controlling and monitoring system in order to achieve proper elimination of IDDs in the community.

KEYWORDS: Iodine deficiency disorder, iodized salt, urinary iodine concentration, thyroid functions

\section{DOI: http://dx.doi.org/10.4314/ejhs.v24i2.2}

\section{INTRODUCTION}

Deficiencies of essential micronutrients in human nutrition have a significant impact on health and development of children in many countries $(1,2)$. Particularly, iodine deficiency is a serious public health problem in Ethiopia. According to the International Council for the Control of Iodine Deficiency Disorders (ICCIDD) estimate in 2011, about 12 million school age children in Ethiopia live with inadequate iodine; about 66 million people are prone to the risk of iodine deficiency disorders; and Ethiopia is the $1^{\text {st }}$ of the top iodine deficient countries in the world based on national median Urinary Iodine Concentration $<100 \mu \mathrm{g} / \mathrm{L}$ (3).

Iodine deficiency in the diet can result in a variety of health problems such as goiter, mental and physical retardation (cretinism), spontaneous abortions, stillbirths, congenital abnormalities, and infant and young child death. Iodine deficiency impedes children's learning ability (4). The clinical and sub-clinical manifestations of iodine deficiency are collectively termed as Iodine Deficiency Disorders (IDD).

\footnotetext{
${ }^{1}$ Department of Chemistry, Bahir Dar University, Ethiopia

${ }^{2}$ Department of Biology, Bahir Dar University, Ethiopia

${ }^{3}$ College of Medicine and Health Sciences, Bahir Dar University, Ethiopia

Corresponding Author: Girma Kibatu, Email: girmak@bdu.edu.et
} 
Although the most visible manifestations of iodine deficiency are goiter and cretinism, many people are affected with less severe deficiencies that are not obvious clinically and not easy to measure but affect wellbeing and productivity.

In Ethiopia, iodine deficiency disorders have been recognized as a major public health problem for the last six decades and remain a major national threat to the health and development of its population $(5,6)$. The most recent data on iodine nutrition status of school aged children and women (2005-2010) indicated that only between 15 and $20 \%$ of the households used adequately iodized salt; the prevalence of goiter in school aged children was greater than $30 \%$ in goiter endemic regions and the median national urinary iodine excretion concentration in school age children was $24.5 \mu \mathrm{g} / \mathrm{L}$ (7). In a cross-sectional community based study conducted in women of childbearing age of 15 to 49 years, the total goiter prevalence (weighed) was $35.8 \%$ (95\% CI 34.5 $37.1) ; 24.3 \%$ were palpable and $11.5 \%$ was visible goiters. The report showed that more than 6 million women were affected by goiter in 2007 (8).

A major focus in the global strategy to eliminate iodine deficiency disorders since 1990 is to introduce universal salt iodization (USI) in deficient areas (9). IDD and USI program in Ethiopia started in 1989, but slowed down drastically in 2000s due to the Ethio-Eretria war when importing iodized salt from the red sea ceased. In 2005, the government of Ethiopia replanned strategies for the achievement of virtual elimination of iodine deficiency disorders by the year 2015 through universal salt iodization (10).

The government revitalized and launched universal salt iodization initiatives in 2009/10 to maintain universal iodized salt distribution throughout the country (11). It has also passed salt regulation requiring that salt for human consumption should be iodized since March 2011(12). Despite some progress in the revitalization of the USI, the country still has one of the highest prevalence of iodine deficiency and one of the weakest salt iodization programs (13).

The successful application of USI in combating IDD requires adequate supplies and regular monitoring. This study assessed the prevalence and severity of IDD among rural school children in Addis-Alem Kebele, Wombera District, in Metekel Zone of Beneshangul-Gumuz, Ethiopia.

\section{METHODS AND MATERIALS}

Study area, design and sampling: A descriptive study of iodine nutrition status among school children based on school survey was conducted in Metekel Zone in Beneshangul Gumuz Region, Ethiopia.

School-based Surveys: If a school-based survey is to be performed, the Ministry of Education should be contacted to obtain a listing of all schools with children of the appropriate age for the survey. A list of all primary and general secondary schools in the Zone where school aged children of 6-18 years were likely to be enrolled were determined. The Menjo Primary and General Secondary School was then selected for the survey by convenience sampling method. Once the school was selected, a specified number of children were selected by systematic random sampling.

Sample size calculation: The sample size $n$ was determined using single population proportion formula. The following assumptions were made: $Z=1.96$ (95\% level of confidence interval); $p=$ 0.48 (the estimate of extended proportion); $D E F F$ $=2$ (the estimated design effect for small population) and $d=0.1$ (the degree of precision, $M R E=10 \%)$. Accordingly, 200 school children aged 6-18 years $($ male $=111$ and female $=89$ ) from a total of 750 school children were selected using systematic random sampling. After numbers were allocated to every child in the school, the first individual was picked using a random table, and subsequent subjects were selected using a fixed interval, i.e. every $\mathrm{n}^{\text {th }}$ person. Random 50 salt sub samples brought to school from households of the sampled children and randomly selected 30 casual urine sub samples from children were collected and measured. 


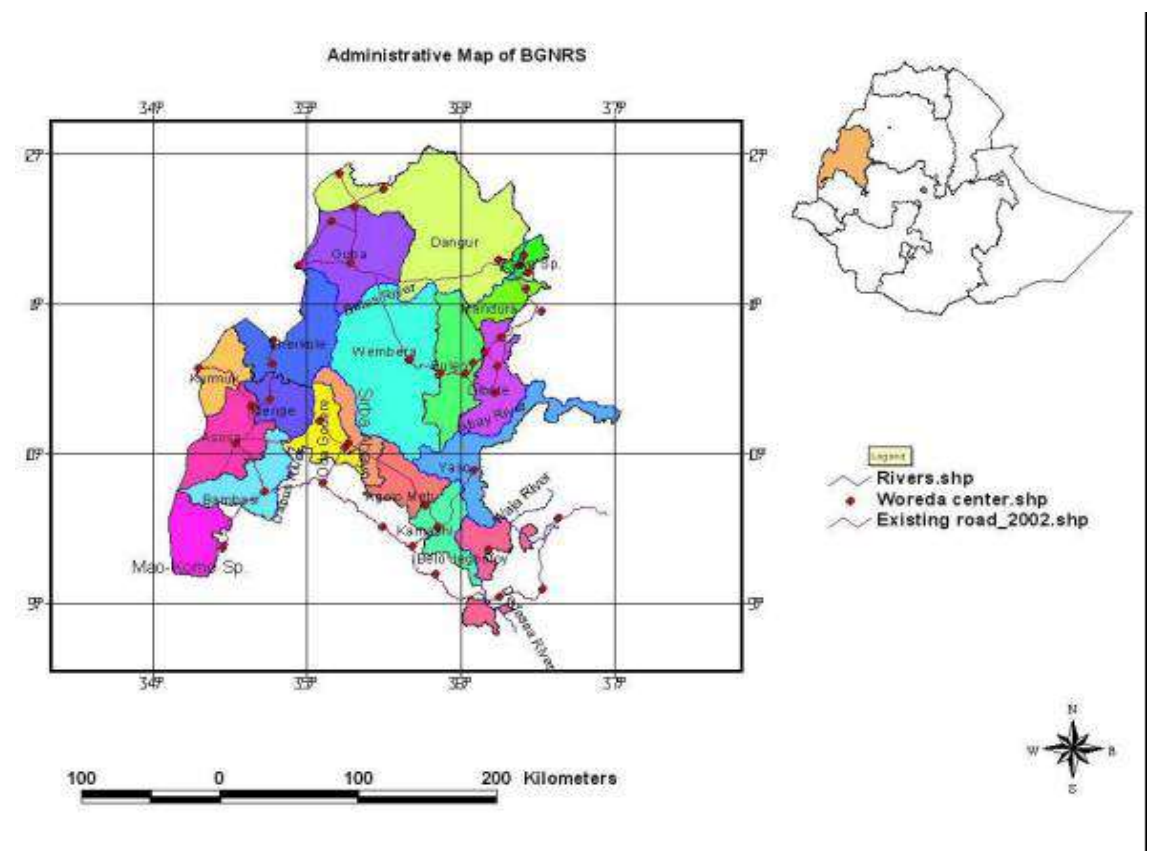

Figure 1: Administrative Map of Beneshangul Gumuz Regional State (BGNRS)

Goiter prevalence: Goiter prevalence was tested using palpation of the neck in 200 selected school aged children in Amuma Primary and General Secondary School. The person who performed the palpation was a health professional with 13 years of working experience as a health officer in the area. The goiter classification and epidemiological criteria for assessing the severity of IDD based on the prevalence of total goitre rate in school children was used based on the recommendation by WHO/UNICEF/ICCIDD (14).

Coverage of iodized salt at household level: A sub-sample of 50 school children was randomly selected from the main sample of 200 students. Each child was provided with screw cap plastic bottle and asked to bring sample of salt from home; household salt samples were collected and carefully transported to Laboratory for measurement. Iodine content in the salt samples was measured using Rapid Salt Testing Kits supplied by UNICEF and iodometric titration. The iodometric titration involved the use of sulphuric acid and potassium iodate as principal reagents, standardized sodium thiosulphates (as titrant) and starch solution (as indicator). After analysis, the salt samples were classified according to their iodine level (15).
Scheme 1: Reaction steps during Titration

1. $\mathrm{IO}_{3}{ }^{-}+5 \mathrm{I}^{-}+6 \mathrm{H}^{+} \longrightarrow 3 \mathrm{I}_{2}+3 \mathrm{H}_{2} \mathrm{O}$

(From salt) (From KI) (From $\mathrm{H}_{2} \mathrm{SO}_{4}$ )

2. $2 \mathrm{Na}_{2} \mathrm{~S}_{2} \mathrm{O}_{3}+\mathrm{I}_{2} \longrightarrow 2 \mathrm{NaI}+\mathrm{Na}_{2} \mathrm{~S}_{4} \mathrm{O}_{6}$

(Sodium thiosulphate) (Sodium tetrathionate)

Urinary iodine concentration: Thirty school children were randomly selected from the main sample of 200 students for urinary iodine excretion test. These children were provided with screw cap plastic bottles and a casual (morning) (5 $\mathrm{ml}$ ) urine sample was collected from each child under the supervision of the researchers. Samples were put in an ice-packed cool box and transported to the Ethiopian Nutrition and Health Research Institute Laboratory for measurement. Iodine concentration in urine samples was determined using Sandell-Kolthoff Reaction in which urine was digested first with ammonium persulphate (16).

The concentration of iodine was determined from its catalytic reduction of ceric ammonium sulphate in the presence of arsenious acid. A spectrophotometer ( $\mathrm{Uv}$-Vis) was used to examine the reduction of ceric ammonium sulphate (yellow). The disappearance of the yellow colour is proportional to the amount of iodine present in the sample. A standard iodine solution was used in order to extrapolate the concentrations of iodine. 
After determination, the concentration of iodine was recorded in micrograms of iodine per liter of urine and classified according to IDD status.

\section{Scheme 2: Sandell-Kolthoff reactions}

$$
\begin{array}{llll}
\mathrm{As}^{3+}+ & \mathrm{I}_{2} & \rightarrow \mathrm{As}^{5+}+2 \mathrm{I}^{-} \\
2 \mathrm{Ce}^{4+}+ & 2 \mathrm{I}^{-} & \rightarrow & 2 \mathrm{Ce}^{3+}+\mathrm{I}_{2} \\
(\text { Yellow }) & & & (\text { Colorless })
\end{array}
$$

Blood constituents: Thirty-seven school children (19 males and 18 females) were randomly selected from the main sample of 200 students who consented for thyroid function tests, and were provided blood samples. Approximately, $5 \mathrm{ml}$ of venous blood samples were drawn from each child by a trained nurse; ethylene diamine tetra acetic acid was used as anticoagulant; serum samples were immediately prepared by centrifugation and frozen in an ice-packed box before being transported. Frozen samples of serum were then transported to Bahir Dar Regional Health Research Laboratory, and stored at a temperature of $-20{ }^{\circ} \mathrm{C}$ for 10 days before analysis. The serum samples were then analyzed for total serum throxine (TT4), total serum triiodothyronine (TT3) and thyroid stimulating hormore (TSH) using Automatic Enzyme Immnunosorbent Assay (ELISA) Analyzer (Model-A3, HUMAN GBD $\mathrm{mbH}$, Wiesbaden, Germany) technique using appropriate reagent kits (17). After analysis of the blood constituents, results were interpreted according to the recommended normal ranges in iodine sufficient children and adults by the American Association of Clinical Endocrinologists Guidelines (18).

Data processing and analysis: Statistical package for Social Sciences (SPSS) software version 17 was used to summarize and analyze the data. Descriptive statistics for all variables were computed and associations between variables were tested using chi-square test. A value of $\mathrm{P}<0.05$ was considered statistically significant.

Ethical approval: The study was approved by the Review Committee of Bahir Dar University, and written consent was obtained from local health and education authorities. Permission for collecting urine and blood samples was obtained from the parents or guardians of each pupil through the school director and parent committee prior to the survey. Children who declined participation were substituted with other students selected randomly from the sample frame.

\section{RESULTS}

Evaluation of the Goiter Prevalence: A total of 200 school children aged 6-18 years were clinically examined for goiter. Out of the 200 students screened for goiter, $16(8 \%)$ had goiter of grade 2 , or a visible goiter and $63(31.5 \%)$ had grade 1 goiter, i.e.79 $(39.5 \%)$ of them had goiter of a certain grade. The prevalence is higher in girls than in boys. There was no significant association

\begin{tabular}{|c|c|c|c|c|c|c|}
\hline Variables & $\begin{array}{l}\text { Grade 0 } \\
\mathbf{N}(\%)\end{array}$ & $\begin{array}{l}\text { Grade } 1 \\
\text { N }(\%)\end{array}$ & $\begin{array}{l}\text { Grade } 2 \\
\mathbf{N}(\%)\end{array}$ & $\begin{array}{l}\text { TGR } \\
\text { N }(\%)\end{array}$ & $\chi^{2}$ & P-Value \\
\hline $\begin{array}{l}\text { Age } \\
6-12(n=117) \\
13-18 \quad(n=83)\end{array}$ & $\begin{array}{l}72(61.54) \\
49(59.04) \\
\end{array}$ & $\begin{array}{l}37(31.62) \\
26(31.32)\end{array}$ & $\begin{array}{l}8(6.84) \\
8(9.64)\end{array}$ & $\begin{array}{l}45(38.46) \\
34(40.96)\end{array}$ & 0.528 & 0.768 \\
\hline $\begin{array}{l}\text { Sex } \\
\text { Male }(n=111) \\
\text { Female }(n=89)\end{array}$ & $\begin{array}{l}76(68.5) \\
45(50.6)\end{array}$ & $\begin{array}{l}28(25.2) \\
35(39.3)\end{array}$ & $\begin{array}{l}7(6.3) \\
9(10.1)\end{array}$ & $\begin{array}{l}35(31.5) \\
44(49.4)\end{array}$ & 6.63 & 0.036 \\
\hline Total $(n=200)$ & $121(60.5)$ & $63(31.5)$ & $16(8)$ & $79(39.5)$ & & \\
\hline
\end{tabular}
between age and goiter prevalence in this study.

Table 1: Age and sex-specific goiter prevalence in schoolchildren of Amuma District, Addis Alem Kebele, 2011

Evaluation of Iodine Content in Salt Intake: Salt for human consumption was abundantly available in the study area. However, salt samples obtained from the households were found to be non-iodized
(60\%), insufficiently iodized (30\%), and only $10 \%$ were adequately iodized (Table 2). Forms of salt used by the households were fine $(n=14,28 \%)$ or coarse $(n=36,72 \%)$. 
Table 2: Iodine content of household salt samples $(n=50)$, Amuma2011

\begin{tabular}{l|ll}
\hline Iodine content & Number of samples & Proportion (\%) \\
\hline Non-iodated $(<5 \mathrm{ppm})$ & 30 & 60 \\
Insufficiently iodated $(5-14 \mathrm{ppm})$ & 15 & 30 \\
\hline Adequately iodated $(15-45 \mathrm{ppm})$ & 5 & 10 \\
Over-iodated $(>45 \mathrm{ppm})$ & - & - \\
\hline
\end{tabular}

\section{Evaluation of concentration of Urinary Iodine}

Excretion: A sub-sample of 30 school children (11 females and 19 males) was randomly selected from the main sample of 200 for urinary iodine excretion test. Median urinary iodine concentration of the school children was $39.9 \mu \mathrm{g} / \mathrm{L}$ with minimum and maximum values of 20.54 $\mu \mathrm{g} / \mathrm{L}$ and $62.2 \mu \mathrm{g} / \mathrm{L}$, respectively. One fifth (20\%) of the school children had mild iodine deficiency, while $80 \%$ had moderate iodine deficiency.

Table 3: Classification of children according to IDD status using urinary iodine concentration (UIC) $(n=30)$, Amuma, 2011

\begin{tabular}{l|cc}
\hline Iodine status (UIC) & Frequency & Proportion (\%) \\
\hline Severe deficiency $(<20 \mu \mathrm{g} / \mathrm{L})$ & - & - \\
Moderate deficiency $(20-49 \mu \mathrm{g} / \mathrm{L})$ & 24 & 80 \\
\hline Mild deficiency $(50-99 \mu \mathrm{g} / \mathrm{L})$ & 6 & 20 \\
Optimal $(100-199 \mu \mathrm{g} / \mathrm{L})$ & - & - \\
\hline More than adequate $(200-299 \mu \mathrm{g} / \mathrm{L})$ & - & - \\
Excessive $(\geq 300 \mu \mathrm{g} / \mathrm{L})$ & - & - \\
\hline
\end{tabular}

Evaluation of Blood Constituents: A sub-sample of 37 school children (19 males and 18 females) was randomly selected from the main sample of 200 students who consented for thyroid function tests by excluding those with personal or family history of thyroid disease, use of medication and availability of visible goitre. The subjects were then analyzed for total serum throxine (TT4), total serum triiodothyronine (TT3) and thyroid stimulating hormore (TSH) using Enzyme immnunosorbent assay (ELISA). Based on TSH thyroid function test, the total thyroid dysfunction was $45.95 \%$ in which $18.92 \%$ were with elevated TSH values and $27.03 \%$ were with suppressed TSH levels. Further analysis of TT4 and TT3 tests in the samples indicated possible primary hyperthyroidism (18.92\%), secondary hyperthyroidism $(16.2 \%)$ or T3 Toxicosis $(5.4 \%)$ and subclinical hyperthyroidism $(2.7 \%)$ rather than hypothyroidism. The algorithm for diagnosing hyperthyroidism from the American Family Physician was used for the analysis (19).

\section{DISCUSSION}

Generally, the household characteristics observed in this study reflected a typical rural area with agriculture, specially crop production and animal husbandry, as the main activity for subsistence. Total goiter rate in this study area among school children was found to be $39.5 \%$ (grade $1=31.5 \%$, grade $2=8 \%$ ), indicating that IDD is a severe public health problem in the kebele according to WHO/UNICEF/ICCIDD recommendations (14, 19). Previous data on iodine nutrition status of women and school aged children in Ethiopia indicated the prevalence of goiter in school age children was greater than $30 \%$, an indication of severe iodine deficiency, in goiter endemic regions including Beneshangul Gumuz (7).

The most recent data on coverage of iodized salt in Ethiopia (2005-2010) indicated that only between 15 and $20 \%$ of the households used adequately iodized salt nationally (20). According to the recent Ethiopian Demography and Health Survey (EDHS 2011), the highest coverage of iodized salt in households (39.7\%) has been reported for Beneshangul Gumuz. In this study, however, only $10 \%$ of the household salt samples were sufficiently iodized and $30 \%$ were insufficiently iodized and the rest $60 \%$ were noniodated. The coverage is much below what is recommended by international organizations, that is $90 \%$ or more households should consume adequately iodated salt for optimum iodine nutrition in a given community. 
Urinary iodine concentration in community members is a good index of iodine intake, and school children have been widely recommended as representative group to assess the state of iodine deficiency in an area. Medians of urinary iodine concentration have been classified by WHO/UNICEF/ICCIDD as follows: (1) less than $20 \mu \mathrm{g} / \mathrm{L}$ : insufficient, severe iodine deficiency; (2) $20-49 \mu \mathrm{g} / \mathrm{L}$ : insuffient, moderate iodine deficiency; (3) $50-99 \mu \mathrm{g} / \mathrm{L}$ : insufficient, mild iodine deficiency; (4) $100-199 \mu \mathrm{g} / \mathrm{L}$ : adequate, optional; (5) $200-299 \mu \mathrm{g} / \mathrm{L}$ : more than adequate; (6) greater than $300 \mu \mathrm{g} / \mathrm{L}$, risk of adverse consequences. The median urinary iodine concentration $(39.9 \mu \mathrm{g} / \mathrm{L})$ found in this study confirms that the area is moderately affected by iodine deficiency. This value is greater than national median urinary iodine excretion concentration of $24.5 \mu \mathrm{g} / \mathrm{L}$ determined in school age children in Ethiopia in 2005, which is an indication of the recent progress but it is still lower than the usually accepted median value of $100 \mu \mathrm{g} / \mathrm{L}$.

In this study, the palpation results of goiter show prevalence of $39.5 \%$, which according to the suggestion of ICCIDD, is an indication of severe iodine deficiency in an endemic goiter region with a long history of deficient nutritional iodine. Only $40 \%$ of the children's households obtained iodized salt of some level (10\% sufficiently iodized; $30 \%$ insufficiently iodized). However, median urinary iodine concentration which is sensitive to the current iodine intake in the diets of the school children was found to be $39.9 \mu \mathrm{g} / \mathrm{l}$, which is in the moderate deficiency range according to the suggestion of the ICCIDD.

Some of the risks associated with the introduction of salt iodization to combat IDD, especially in previously severe iodine deficient populations, are the introduction of excessively iodized salt and iodine induced hyperthyroidism $(21,22)$. None of the salt samples collected from the children's households was over iodized. Results from school children's blood constitutes showed total thyroid dysfunction of $45.95 \%$ based on TSH values in which $18.92 \%$ of the children indicated elevated, and $27.03 \%$ of them showed suppressed TSH levels. Further analysis of TT4 and TT3 tests in the samples indicated more hyperthyroidism and thyrotoxicity than hypothyroidism. The high prevalence of hyperthyroidism could be iodine-induced hyperthyroidism (IIH) due to the recent introduction of iodized salt in their diet. The population is in a transition phase form iodine deficient to iodine sufficient as revealed by the median UIC and evidence of transient iodineinduced hyperthyroidism. This has been observed in epidemic incidents in several countries where iodine was given as prophylaxis in a variety of vehicles (23). The occurrences of transient IIH in previously iodine deficient areas undergoing new iodization program is mild and self-limited (24).

The successful application of USI in combating IDD in a country requires adequate supplies and regular monitoring at the production and consumption levels. Universal salt iodization has to go hand in hand with laboratory development, research, capacity building, advocacy and public education on IDD. Commitment of health professionals and researchers to the assessment and reassessment of the progress in iodine nutrition status is critical for tracking progress towards sustainable elimination of iodine deficiency disorders (25). Iodine deficiency is still a severe public health problem in the district. There is a need to further strengthen the existing controlling and monitoring system for the quality of iodized salt distribution. Careful evaluation of the impact on the society is also necessary in order to achieve proper elimination of IDDs in the community. Results from such efforts are vital for policy and program management decisions aiming to prevent and control IDD.

\section{ACKNOWLEDGMENTS}

The authors are grateful to the Research \& Community Services Office of Bahir Dar University for supporting the study financially. Graduate students Fekadu, Getaye and Minalu for their participation in collecting data. We would also like to thank the administration and staff of Amuma Primary and General Secondary School who participated in the study along with the school children and their parents. We also acknowledge the support we received from the Ethiopian Nutrition and Health Research Institute and the Bahir Dar Regional Health Research Laboratory Centre for allowing us to use their facilities to measure urinary iodine concentrations and blood constituents for the study samples. 


\section{REFERENCES}

1. Zimmermann MB, Jooste PL, Pandav CS. Iodine-deficiency disorders. Lancet 2008; 372: 1251-62.

2. Andersson M, Zimmerman MB. Global iodine nutrition: a remarkable leap forward in the past decade. IDD Newsletter 2012; 40 (1): 1-5.

3. Andersson M, Karumbunathan V, Zimmerman MB. Global iodine status in 2011 and trends over the past decade. J Nutr 2012; 142 (4):740-50.

4. Yinebeb M, Andualem M, P.N. Rajish, Getenet B. Prevalence and severity of iodine deficiency disorders among children 6-12 years of age in Shebe Senbo district, Jimma Zone, Southwest Ethiopia. Ethiop J Health Sci. 2012; 22(3): 196 - 204.

5. Bogale A. Iodine status and cognitive functions of women and their five year old children in rural Sidama. Ease Africa J Pub H 2009; 6(3):296-299.

6. Cherinet A, Kelbessa U. Determinants of iodine deficiency in school children in different regions of Ethiopia. East African Med J 2000; 77:133-37.

7. Cherinet A, Yemane B, Girma A, Zewditu G, Tesema E. Prevalence of goiter in children 6 to 12 years of age in Ethiopia. Food and Nutr Bull 2007; 8(4): 391-98.

8. Cherinet A., and Yemane B. The goitre rate, its association with reproductive failure, and the knowledge of iodine deficiency disorder (IDD) among women in Ethiopia: Crosssection community based study. BMC Pub $H$ 2007; 7: 316-19.

9. World Health Organization/United Nations Children's Fund/International Council for Control of Iodine Deficiency Disorders. Indicators for assessing iodine deficiency disorders and their control through salt iodization. Geneva, World Health Organization 1994.

10. Ethiopian Federal Ministry of Health. National Guideline for Control and Prevention of Micronutrient Deficiencies. Addis Ababa: Ministry of Health, 2004.

11. Ethiopian Federal Ministry of Health/United Nations Children's Fund/Micronutrient Initiative. The Ethiopian National Salt Iodization Launching and Scale-Up program.
Addis Ababa, Ethiopian Ministry of Health, 2009.

12. Federal Democratic Republic of Ethiopia. Regulation No.204/2011 Salt Iodization Council of Ministers Regulation. Fed Negarit Gaz FDRE 2011; 17(28):5785-86.

13. International Council for Control of Iodine Deficiency Disorders. Elimination of iodine deficiency through salt iodization in Ethiopia. Summary Report on Situation Analysis of IDD and USI in Ethiopia, ICCIDD 2012.

14. World Health Organization/United Nations Children's Fund/International Council for control of Iodine Deficiency Disorders. Assessment of iodine deficiency disorders and monitoring their elimination. A Guide for Programme Managers, $3^{\text {rd }}$ ed. Geneva: World Health Organization, 2007.

15. K. B. M. Kulwa, K. Kamuzora and G. Leo. Urinary iodine concentration and availability of iodated salt in school children in goitre endemic district of Tanzania. East African Med $J$ 2006; 83(4): 79-84.

16. World Health Organization. Recommended iodine levels in salt and guidelines for monitoring their adequacy and effectiveness. WHO micronutrient series WHO/NUT/96. 13, 2. WHO/UNICEF/ICCIDD. Geneva, 1996.

17. Stockig JR. Measurement of Thyroxine and Triiodothyronine: The basis of Total and Free Thyroid hormone Methodology. In: Brent GA, editor. Thyroid function testing, Los Angeles, CA, USA, 2010.

18. American Association of Clinical Endocrinologists. AACE medical guidelines for clinical practice for the evaluation and treatment of hyperthyroidism and hypothyroidism. Thyroid Guidelines, Endocr Pract. 2002; 8(6): 457-67.

19. Jeri RR and Stephen NW. Hyperthyroidism: Diagnosis and treatment. American Family Physician, 2005; 72 (4): 626.

20. Central Statistics Authority of Ethiopia/ICF International. Ethiopia Demographic and Health survey 2011, Addis Ababa/Maryland, 2012.

21. Stanbury JB, Ermans, AE, Bourdoux P, Todd C, Oken E, Tonglet R, Vidor G, Braverman LE, and Medeiros-Neto E. Iodine-Induced Hyperthyroidism: Occurrence and Epidemiology. Thyroid. 1998; 8(1): 83-100. 
22. Cherinet, A, Gonfa, A, Melaku, U, Hana, N. Thyroid responses to varying doses of oral iodized oil in school children in Hawassa, Ethiopia. Ethio health Dev 2000; 14: 49-55.

23. Delange F, de Benoist B, and Alnwick D. Risks of Iodine-Induced Hyperthyroidism after Correction of Iodine Deficiency by Iodized Salt. Thyroid. 1999; 9(6): 545-556.
24. Dunn JT, Semigran MJ, and Delange F. The Prevention and Management of IodineInduced Hyperthyroidism and its Cardiac Features. Thyroid. 1998, 8(1): 101-106.

25. Kapil Y. Iodine deficiency in the democratic people's republic of Korea. IDD Newsletter, 2012; 40 (4): 10-14. 